\title{
Raman Spectroscopy Characterization of Aqueous Vanadate Species Interaction with Aluminum Alloy 2024-T3 Surfaces
}

\author{
B. L. Hurley, ${ }^{\mathrm{z}}$ S. Qiu, and R. G. Buchheit ${ }^{*, \mathrm{z}}$ \\ Fontana Corrosion Center, Department of Materials Science and Engineering, The Ohio State University, Columbus, \\ Ohio 43210, USA
}

\begin{abstract}
Raman spectroscopy and electrochemical techniques were used to characterize the interactions of aqueous $\mathrm{NaVO}_{3} / \mathrm{NaCl}$ and $\mathrm{NH}_{4} \mathrm{VO}_{3}$ /oxalic acid with AA 2024-T3. The interaction of aqueous $\mathrm{NaVO}_{3}$ with $\mathrm{Cu}^{0}$ and $\mathrm{Cu}_{2} \mathrm{O}$ was characterized. At potential values similar to the OCP of AA 2024-T3 in dilute $\mathrm{NaCl}$, aqueous $\mathrm{NaVO}_{3}$ formed a polyvanadate film on $\mathrm{Cu}_{2} \mathrm{O}$ and formed little or no vanadate film on $\mathrm{Cu}^{0}$. Treatment of AA 2024-T3 with basic, aqueous $\mathrm{NaVO}_{3} / \mathrm{NaCl}$ resulted in a polyvanadate film on copper-rich intermetallic particles and the formation of monovanadates on the matrix. Treatment of AA 2024-T3 with acidic, aqueous $\mathrm{NH}_{4} \mathrm{VO}_{3}$ /oxalic resulted in the formation of monovanadates on the matrix and provided no evidence of vanadate species on copper-rich particles. AA 2024-T3 samples pretreated with either aqueous vanadate salt solution displayed modest cathodic inhibition soon after treatment but inhibition degraded with aging. The formation of polymerized vanadates species on copper-rich particles supports the cathodic inhibition mechanism. The presence of vanadate species on copper-rich particles pretreated with aqueous $\mathrm{NaVO}_{3} / \mathrm{NaCl}$ containing predominantly tetrahedral vanadates versus the lack of evidence for similar species on particles treated with aqueous $\mathrm{NH}_{4} \mathrm{VO}_{3}$ /oxalic acid containing predominantly octahedral vanadates supports the importance of tetrahedrally coordinated vanadate species for corrosion inhibition.

(c) 2011 The Electrochemical Society. [DOI: 10.1149/1.3562557] All rights reserved.
\end{abstract}

Manuscript submitted September 30, 2010; revised manuscript received January 11, 2011. Published March 22, 2011.

Chromate provides excellent corrosion inhibition properties on aluminum alloys. Unfortunately, its outstanding corrosion protection does not outweigh its detrimental effects on the environment, particularly as those effects relate to health and safety issues. Therefore, although chromate is capable of providing excellent corrosion inhibition, there is a strong impetus to replace it. In the search for replacements for chromate-based inhibition systems, vanadates have received much well-deserved attention. ${ }^{1-7}$ In addition to promising corrosion inhibition testing results, vanadates share many of the distinctive characteristics that have been found to support chromate's superior ability to inhibit corrosion such as a range of oxidation states (including more than one stable oxidation state), a variety of coordination geometries, and the ability to act as an insulator, a semi-conductor, and/or a conductor. ${ }^{8}$ To date, experimental work on vanadate inhibition has focused on vanadate speciation in solution, the inhibiting action of vanadates on $\mathrm{Al}$ alloys, the corrosion cell process, and the oxygen reduction reaction. ${ }^{1-7}$ Specifically, Frankel et al. and Buchheit et al. reported that treatment of AA 2024-T3 ("2024") with basic aqueous vanadate solutions which contain predominantly tetrahedrally coordinated metavanadates provided cathodic protection of 2024 while treatment with acidic vanadate solutions which contain predominantly octahedrally coordinated vanadates did not provide significant corrosion protection. ${ }^{1-7}$ Other efforts have focused on the delivery of vanadates in conversion coatings 9 and high solids primer-like organic coating formulations. ${ }^{10}$

This work looks at the manner in which aqueous vanadate salts interact with an aluminum alloy surface and how these interactions might lead to corrosion inhibition. In particular, this work addresses the manner in which vanadates interact with the copper-rich intermetallic particles found in many aluminum alloys.

The alloying of aluminum with copper, magnesium, manganese and other metals enhances the mechanical properties of the alloy; however, it also leads to the presence of intermetallic particles whose electrochemical characteristics differ significantly from those of the aluminum matrix. ${ }^{11,12}$ Consequently, all of the $2 \mathrm{XXX}$ series aluminum alloys are prone to localized corrosion, particularly pitting and stress corrosion cracking, arising from the inhomogeneous distribution of copper in these alloys. Localized corrosion associated with micrometer-sized intermetallic particles has been interpreted in the context of a local galvanic cell action, and local cathodic corrosion. ${ }^{13-22}$ Despite any differences in mechanistic interpretation of localized corrosion at constituent intermetallic particles in alloy

* Electrochemical Society Fellow.

z E-mail: hurley.50@osu.edu; buchheit.8@osu.edu
2024 , it is clear that inhibition of oxygen reduction on those particles is necessary to limit corrosion. Approximately $60 \%$ of the secondary phase intermetallic particles with a diameter greater than about $0.5-0.7 \mu \mathrm{m}$ found in 2024 are copper-rich $\mathrm{Al}_{2} \mathrm{CuMg} .{ }^{17}$ While the aluminum matrix on 2024 readily passivates, copper-rich intermetallic particles typically do not and they, therefore, provide excellent sites for the cathodic oxygen reduction reaction ("ORR"). One mechanism by which chromate is presumed to inhibit corrosion on 2024 is by the formation of an irreversibly adsorbed chromium oxide film on the cathodic intermetallic particles that inhibits the ORR on those particles. ${ }^{23,24}$ Viable replacements for chromate-based corrosion inhibition systems will most likely need to replicate this inhibition process.

There is plentiful and rich literature related to the catalytic use of vanadium oxides supported on alumina and other metal oxides for both oxidation and reduction reactions. ${ }^{25-36}$ In particular, there are noteworthy studies of the catalytic properties of mixed vanadiummetal oxides showing significant variations in surface redox properties depending on the identity of the metal. ${ }^{30}$ As discussed below, vanadium-copper mixed oxides have specifically exhibited unique redox properties that might shed light on the ability of vanadates to inhibit the ORR. ${ }^{30}$ The findings in the literature on metal oxide supported vanadate catalysts relate to the mechanism by which such catalysis occurs, involving the exchange of oxygen atoms on the vanadium oxide surface between molecular oxygen and oxygen atoms contained in the vanadate species. ${ }^{30,31}$ Although treating alumina and other pure metal oxides with vanadium oxides is different than reacting vanadates on the matrix aluminum oxide and intermetallic particles of an aluminum alloy, it is reasonable to assume that similar mechanisms could exist and there are some lessons that can be learned and extended to the use of vanadates for corrosion inhibition on aluminum alloys.

Recent work suggests that vanadate corrosion protection is primarily associated with inhibition of the ORR on 2024..$^{1,2,5-7}$ This, in turn, suggests that the interaction of vanadates with copper-rich intermetallic particles plays an important role in the inhibition process. This work uses electrochemical techniques combined with Raman spectroscopy to analyze the interaction of two forms of vanadate salts with copper and copper-rich intermetallic particles on 2024. The majority of this work involves the treatment of 2024 with aqueous $\mathrm{NaVO}_{3}$ in a manner similar to previous corrosion inhibition work. Additionally, aqueous acidic solutions of $\mathrm{NH}_{4} \mathrm{VO}_{3}$, a vanadate species commonly employed in catalytic work, were used to treat 2024. The interaction of vanadates with the aluminum matrix is compared to and contrasted with that of copper-rich intermetallic particles. 


\section{Experimental}

Materials.-All chemicals were reagent grade and were used as received. All solutions were prepared and all rinsing was performed with deionized water (minimum of $18.2 \mathrm{M} \Omega^{*} \mathrm{~cm}$ resistivity). Copper rod (99.9\%) was acquired from Alfa Aesar. $\mathrm{NaVO}_{3}(\geq 98 \%)$ was acquired from Fluka Chemika. $\mathrm{NH}_{4} \mathrm{VO}_{3}(\geq 99 \%)$ was acquired from Sigma-Aldrich. Using the method adapted from Bell et al., a $30 \mathrm{mM}$ $\mathrm{NH}_{4} \mathrm{VO}_{3}$, oxalic acid solution was prepared by adding $0.2 \mathrm{mmol}$ $\mathrm{NH}_{4} \mathrm{VO}_{3}$ to $0.4 \mathrm{mmol}$ of oxalic acid dissolved in $1 \mathrm{ml} \mathrm{DI}$ water and diluting to $6 \mathrm{ml}$, resulting in a 1:2 molar ratio of $\mathrm{NH}_{4} \mathrm{VO}_{3}$ :oxalic acid and a $p \mathrm{H}$ of $\sim 3$. $^{32}$

Instrumentation.-Raman spectroscopic experiments.-All Raman spectra in this work were acquired on a Renishaw inVia Raman microprobe system. Reference spectra of solid $\mathrm{VO}_{2}, \mathrm{~V}_{2} \mathrm{O}_{5}$, $\mathrm{NaVO}_{3}$, and $\mathrm{V}_{2} \mathrm{O}_{3}$ were acquired with $514 \mathrm{~nm}$ excitation at a power of $0.25 \mathrm{~mW}$ and an integration time of $20 \mathrm{~s}$ with ten accumulations. A reference spectrum of solid $\mathrm{V}_{2} \mathrm{O}_{4}$ was acquired with $633 \mathrm{~nm}$ excitation at a power of $2 \mathrm{~mW}$ and an integration time of $10 \mathrm{~s}$ with two accumulations. Raman spectra of the copper rod were acquired with $633 \mathrm{~nm}$ excitation with a Leica $5 \mathrm{X}$ objective at a power of $4 \mathrm{~mW}$ and an integration time of $10 \mathrm{~s}$ with one accumulation. Raman spectra of treated and untreated 2024 samples (matrix and intermetallic particles) were acquired with $514 \mathrm{~nm}$ excitation with a Leica 50X objective at a power of $5 \mathrm{~mW}$, and an integration time of $10 \mathrm{~s}$ with ten accumulations. With the exception of the unique spectrum shown in Fig. 9, all spectral results, including those of aged samples of 2024 treated with $\mathrm{NaVO}_{3}$ (not shown), were replicated a minimum of three times.

Potentiodynamic and potentiostatic experiments.-A Gamry Reference 600 was employed with a standard 3-electrode setup for all electrochemical work. A saturated calomel electrode (SCE) served as the reference electrode and a Pt wire was employed as the counter electrode. All given potential values are relative to an SCE. All experiments were performed with the cell solution surface exposed to air. Potentiodynamic scans were performed at $0.5 \mathrm{mV} / \mathrm{s}$. Electrochemical results were replicated a minimum of three times.

Sample preparation.-Copper substrate.-A copper rod was hand-polished with silicon carbide paper (Buelher 180 grit) wetted with DI water, rinsed in DI water, and air dried. Electrochemical copper deposition was used to roughen the surface, which promotes surface enhancement on copper samples excited with $633 \mathrm{~nm}$ light. Using a method adapted from Kudelski et al., deposition was accomplished by immersing approximately $6 \mathrm{~cm}$ of the rod in an unstirred solution of $500 \mathrm{mM} \mathrm{CuSO}_{4}$ and holding it at a potential of $-100 \mathrm{mV}$ for $45 \mathrm{~min} .{ }^{37}$ The roughened rod was immediately rinsed in DI water and approximately $1 \mathrm{~cm}$ of the rod was immersed in an electrochemical cell containing $20 \mathrm{ml}$ of $100 \mathrm{mM} \mathrm{K}_{2} \mathrm{SO}_{4}$ as the electrolyte. The rod was then held at a potential of $-600 \mathrm{mV}$ for five minutes, thereby reducing the surface to $\mathrm{Cu}^{0}$, eliminating copper oxide on the immersed portion. ${ }^{38}$ While maintaining a potential of $-600 \mathrm{mV}, 20 \mathrm{ml}$ of $100 \mathrm{mM} \mathrm{NaVO}$ was then added to the cell, thereby exposing both the lower $\sim 1 \mathrm{~cm}\left(\mathrm{Cu}^{0}\right)$ part of the rod and the $\sim 1 \mathrm{~cm}$ immediately above the $\mathrm{Cu}^{0}$ portion $\left(\mathrm{Cu}_{2} \mathrm{O}\right)$ to a $50 \mathrm{mM}$ $\mathrm{NaVO}_{3}$ solution (final $p \mathrm{H} \sim 8$ ). The potential was held at $-600 \mathrm{mV}$ for an additional $10 \mathrm{~min}$, the rod was removed, thoroughly rinsed in DI water, and air dried. The resulting rod, therefore, contained three different types of surface. On the lower end was a $\mathrm{Cu}^{0}$ surface that had been treated with vanadate at $-600 \mathrm{mV}$, immediately above that section was a section of $\mathrm{Cu}_{2} \mathrm{O}$ that had been treated with vanadate at $-600 \mathrm{mV}$, and immediately above that section was a roughened copper surface $\left(\mathrm{Cu}_{2} \mathrm{O}\right.$, unexposed to vanadate, control).

2024 substrate.-Samples of $2024\left(\sim 4 \mathrm{~cm}^{2} \times 2 \mathrm{~mm}\right)$ were handpolished with successive grades of silicon carbide paper to a maximum grade of P4000 (Buehler) wetted with DI water, rinsed in DI water, and air dried. Polished samples were treated with two different vanadate salts using two different methods: (1) 2024 samples were immersed in $\sim 1 \mathrm{ml}$ of a solution of $100 \mathrm{mM} \mathrm{NaVO}_{3}$ and 100 $\mathrm{mM} \mathrm{NaCl}, p \mathrm{H} \sim 8$. After $60 \mathrm{~min}$, samples were removed, thoroughly rinsed in DI water, and air dried; (2) 2024 samples were lightly coated by placing several drops of the $\mathrm{NH}_{4} \mathrm{VO}_{3}$ /oxalic acid solution described above $(p \mathrm{H} \sim 3)$ on the surface and spreading the drops to a thickness of $\sim 0.5 \mathrm{~mm}$ with the edge of a glass slide, allowed to dry for $\sim 24 \mathrm{~h}$, thoroughly rinsed in DI water, and air dried.

\section{Results}

Reference Raman spectra of various solid vanadate compounds are shown in Fig. 1. Of specific note is the strong peak common to $\mathrm{VO}_{2}, \mathrm{~V}_{2} \mathrm{O}_{5}, \mathrm{~V}_{2} \mathrm{O}_{4}$, and $\mathrm{NaVO}_{3}$ at $992,993,992$, and $944 \mathrm{~cm}^{-1}$, respectively. These spectra also display similar peaks at $\sim 700 \mathrm{~cm}^{-1}$. In particular, the spectra of $\mathrm{VO}_{2}, \mathrm{~V}_{2} \mathrm{O}_{5}$ and $\mathrm{V}_{2} \mathrm{O}_{4}$ are almost identical, with only slight shifts in the strong peaks. The spectrum of $\mathrm{V}_{2} \mathrm{O}_{3}$ is notably different than spectra of the above compounds with the absence of any strong peak between 900 and $1000 \mathrm{~cm}^{-1}$. Likewise, the spectrum of $100 \mathrm{mM} \mathrm{NaVO}_{3}$ (not shown), is dissimilar to that of the solid compounds, including that of solid $\mathrm{NaVO}_{3}$. The spectrum of aqueous $\mathrm{NaVO}_{3}$ displays only two peaks at $\sim 560$ and $\sim 1095 \mathrm{~cm}^{-1}$.

Copper rod.-The reaction of aqueous $\mathrm{NaVO}_{3}$ with a copper rod sample was first used as a model for a similar reaction on copperrich intermetallic particles. As described above, three types of copper surfaces on the rod were analyzed: (1) a control $\mathrm{Cu}_{2} \mathrm{O}$ surface, (2) a $\mathrm{Cu}_{2} \mathrm{O}$ surface treated with vanadate, and (3) a $\mathrm{Cu}^{0}$ surface treated with vanadate. Raman analysis of these three surfaces resulted in three distinctly different spectra (Fig. 2). The unaltered spectra in Fig. 2 were all collected using the same parameters and, therefore, reflect relative intensities. The control surface displayed only the well-established broad Raman bands attributable to $\mathrm{Cu}_{2} \mathrm{O}$ at 525 and $613 \mathrm{~cm}^{-1} \cdot 39,40$ The $\mathrm{Cu}^{0}$ surface treated with vanadate displayed very weak bands at 525 and $613 \mathrm{~cm}^{-1}$, indicating the presence of some $\mathrm{Cu}_{2} \mathrm{O}$ and a weak band at $\sim 768 \mathrm{~cm}^{-1}$. Conversely, the $\mathrm{Cu}_{2} \mathrm{O}$ surface treated with vanadate displayed a strong, somewhat broad band between 650 and $1000 \mathrm{~cm}^{-1}$ with a maximum at $763 \mathrm{~cm}^{-1}$ along with a strong shoulder at $\sim 840 \mathrm{~cm}^{-1}$. This surface also displayed the expected (though weak) bands at 525 and 613 $\mathrm{cm}^{-1}$ due to $\mathrm{Cu}_{2} \mathrm{O}$.

Control 2024 and $\mathrm{NaVO}_{3}$-treated 2024.- Spectra were acquired of both the matrix and copper-rich intermetallic particles of 2024 treated with $\mathrm{NaVO}_{3}$ along with control spectra of untreated 2024 matrix and copper-rich intermetallic particles. The presence of the two distinctive broad bands attributable to $\mathrm{Cu}_{2} \mathrm{O}$ at 525 and $613 \mathrm{~cm}^{-1}$

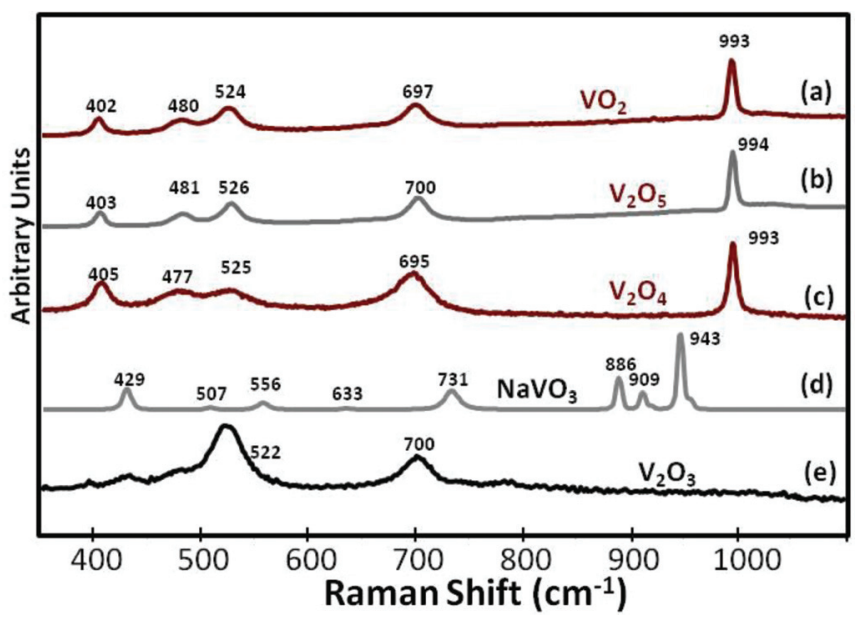

Figure 1. (Color online) Reference Raman spectra of solid vanadate compounds. (a) $\mathrm{VO}_{2}$, (b) $\mathrm{V}_{2} \mathrm{O}_{5}$, (c) $\mathrm{V}_{2} \mathrm{O}_{4}$, (d) $\mathrm{NaVO}_{3}$, (e) $\mathrm{V}_{2} \mathrm{O}_{3}(633 \mathrm{~nm}$ excitation). 


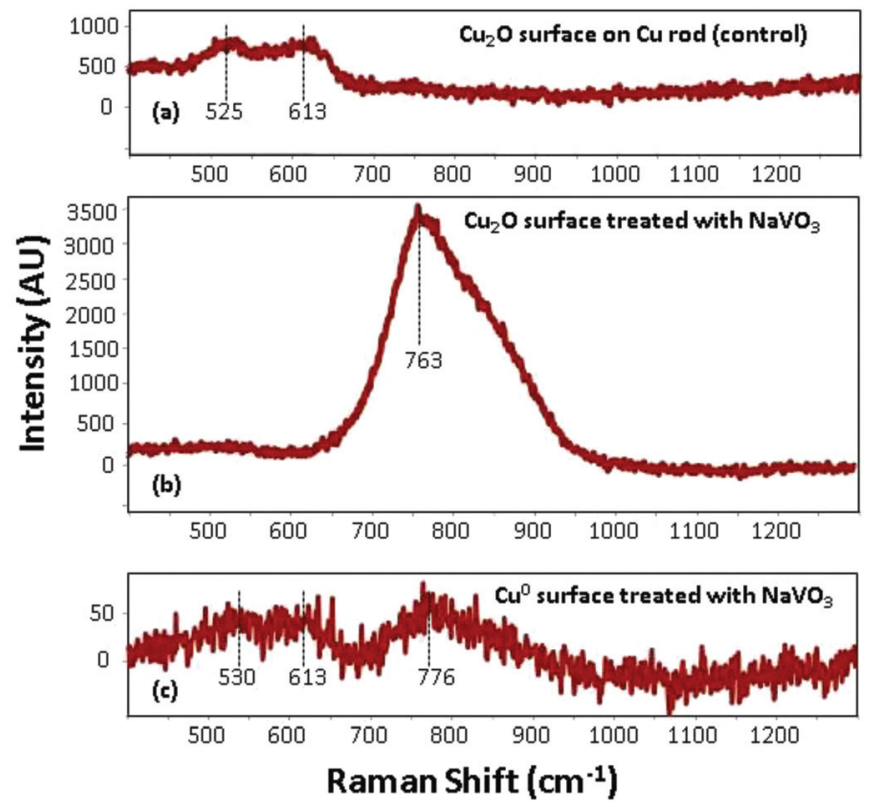

Figure 2. (Color online) Raman spectra of: (a) $\mathrm{Cu}_{2} \mathrm{O}$ surface on $\mathrm{Cu}$ rod (control), (b) $\mathrm{Cu}_{2} \mathrm{O}$ surface treated with $\mathrm{NaVO}_{3}$, (c) $\mathrm{Cu}^{0}$ surface treated with $\mathrm{NaVO}_{3}(633 \mathrm{~nm}$ excitation).

(described above) was used as a marker for copper-rich intermetallic particles. Control spectra of the untreated 2024 (Fig. 3) matrix display a sharp peak at $588 \mathrm{~cm}^{-1}$ combined with a broad band between $\sim 750$ and $950 \mathrm{~cm}^{-1}$ on a rising background. Control spectra of untreated 2024 copper-rich intermetallic particles (Fig. 3) display strong bands at 526 and $613 \mathrm{~cm}^{-1}$. Spectra of the matrix of 2024 treated with $\mathrm{NaVO}_{3}$ displayed a peak at $588 \mathrm{~cm}^{-1}$ and a weak, broad band between 750 and $980 \mathrm{~cm}^{-1}$ (Fig. 4). Additional sharp, weak peaks at 817 and $1036 \mathrm{~cm}^{-1}$ were also observed in several spectra of the matrix of 2024 treated with $\mathrm{NaVO}_{3}$. Similar to the control spectra of the 2024 matrix, these spectra also displayed a rising background.

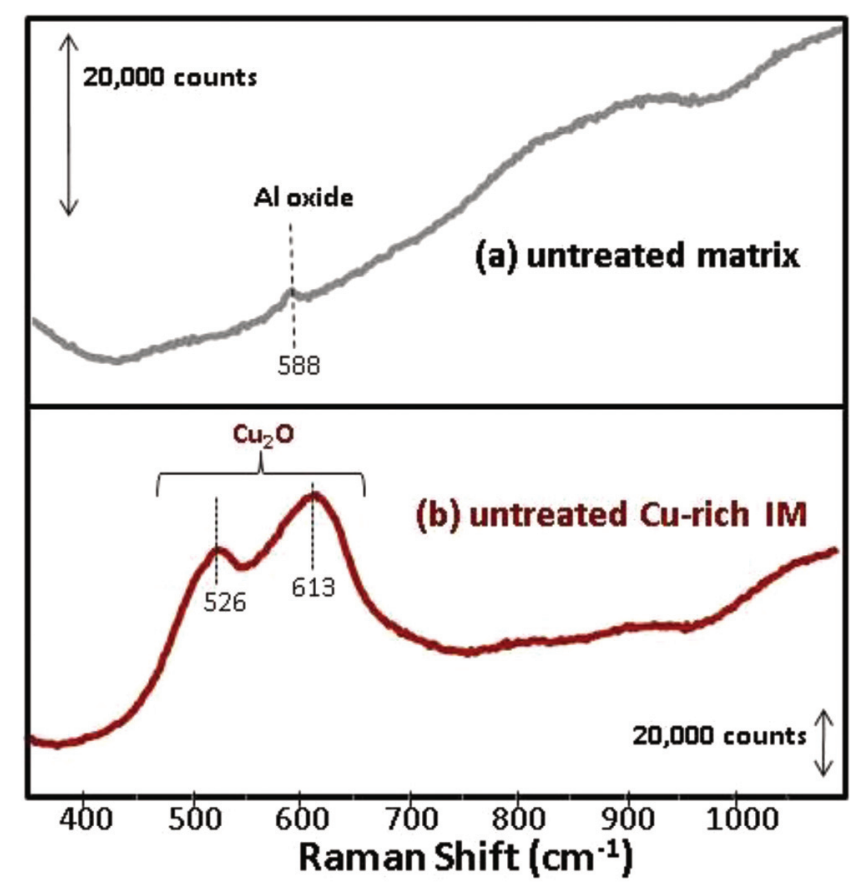

Figure 3. (Color online) Raman spectra of: (a) untreated matrix of 2024, (b) untreated $\mathrm{Cu}$-rich intermetallic particle on 2024 (514 nm excitation).

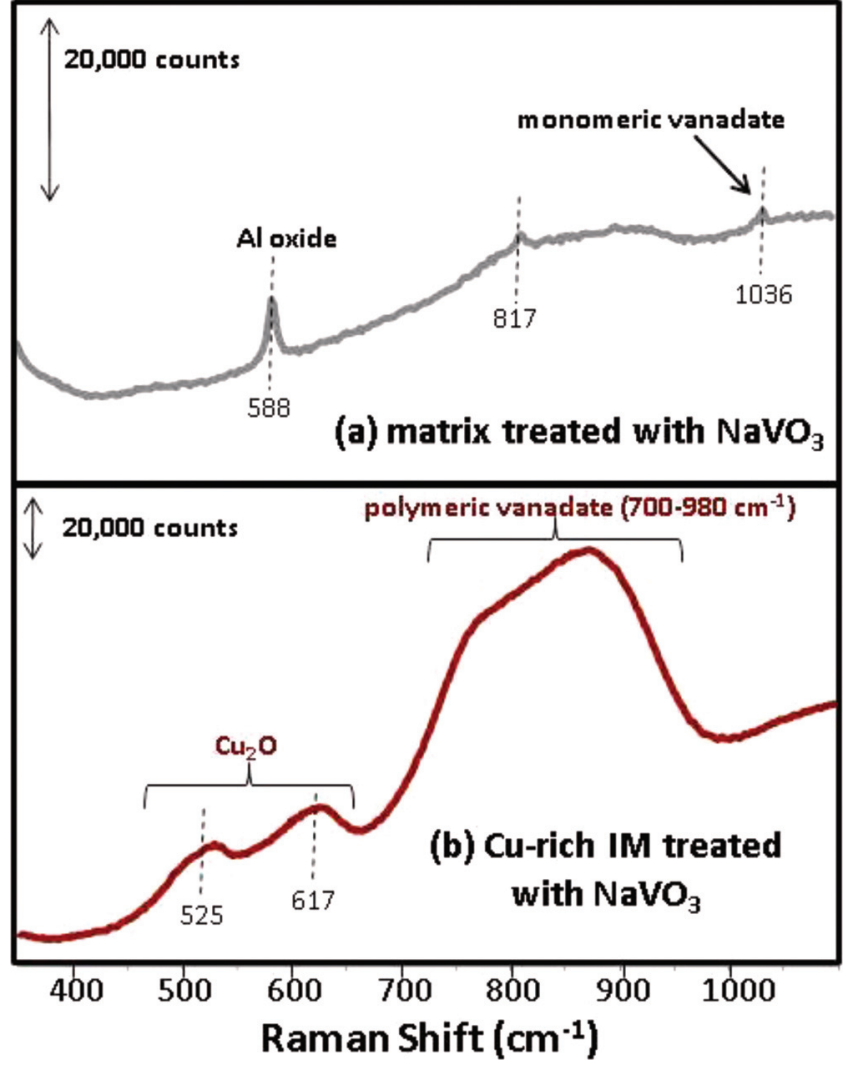

Figure 4. (Color online) Raman spectra of: (a) matrix of 2024 treated with $\mathrm{NaVO}_{3}$, (b) Cu-rich intermetallic particle on 2024 treated with $\mathrm{NaVO}_{3}$ (514 nm excitation).

Spectra of copper-rich particles on 2024 treated with $\mathrm{NaVO}_{3}$ displayed a wide band similar to but much stronger than that of the treated matrix from 700 to $980 \mathrm{~cm}^{-1}$. The maximum of this band appeared at $\sim 875 \mathrm{~cm}^{-1}$ with some spectra displaying a shoulder at $\sim 767 \mathrm{~cm}^{-1}$ as shown in Fig. 4. These spectra did not display a peak above $970 \mathrm{~cm}^{-1}$, and, in particular did not display a peak in the range from 1030 to $1040 \mathrm{~cm}^{-1}$.

$\mathrm{NH}_{4} \mathrm{VO}_{3}$-treated 2024.- Spectra were also acquired of both the matrix and copper-rich particles of 2024 treated with $\mathrm{NH}_{4} \mathrm{VO}_{3}$ /oxalic acid. As in the case of the matrix of 2024 treated with $\mathrm{NaVO}_{3}$, spectra of the matrix of 2024 treated with $\mathrm{NH}_{4} \mathrm{VO}_{3}$ /oxalic acid displayed a peak at $588 \mathrm{~cm}^{-1}$ and a weak, broad band between 750 and $980 \mathrm{~cm}^{-1}$ in combination with sharp, weak peaks at 817 and 1036 $\mathrm{cm}^{-1}$ (Fig. 5). Spectra of 2024 copper-rich particles treated with $\mathrm{NH}_{4} \mathrm{VO}_{3}$ /oxalic acid displayed no discernable features except bands at 526 and $613 \mathrm{~cm}^{-1}$ upon a rising background (Fig. 5).

Cathodic polarization scans performed in $0.1 \mathrm{M} \mathrm{NaCl}$ on 2024 samples pre-treated with either $\mathrm{NaVO}_{3}$ or $\mathrm{NH}_{4} \mathrm{VO}_{3}$ /oxalic acid displayed only modest inhibition to the ORR on samples aged $\sim 24 \mathrm{~h}$ under ambient conditions (Fig. 6) and no inhibition on samples aged $\sim 96 \mathrm{~h}$. No significant difference was noted in the open circuit potential values of the same samples in either case in comparison to control 2024 samples. In all cases the exposed surface area was $1.0 \mathrm{~cm}^{2}$.

\section{Discussion}

The extensive literature related to the use of vanadia catalysts supported on alumina and the orthovanadates of various metal cations also used for catalysts provides substantial background related to reference Raman spectra for alumina-supported vanadates, orthovanadates of various metal cations, and findings related to redox reactions occurring on such surfaces. ${ }^{25-36}$ Additionally, although 


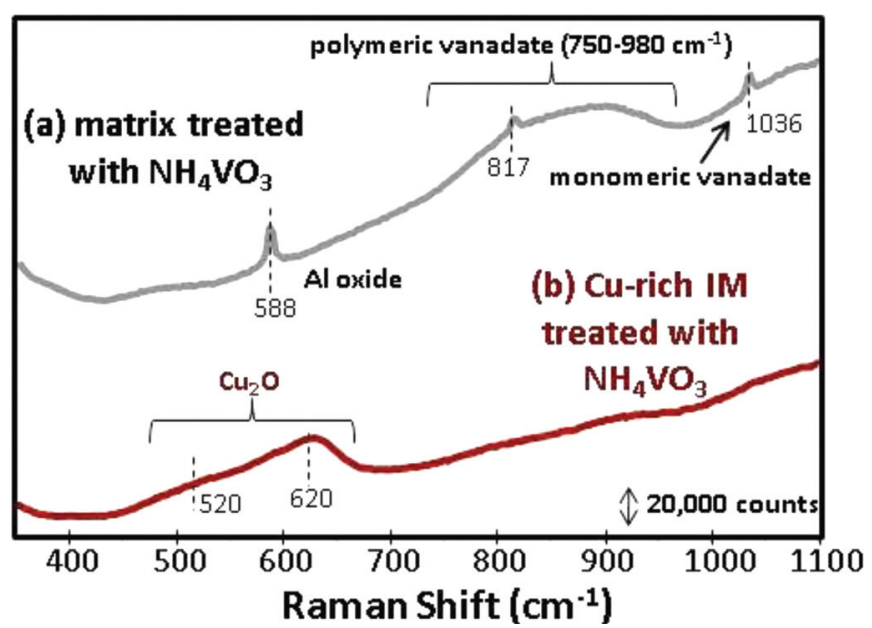

Figure 5. (Color online) Raman spectra of: (a) matrix of 2024 treated with $\mathrm{NH}_{4} \mathrm{VO}_{3}$, (b) Cu-rich intermetallic particle on 2024 treated with $\mathrm{NH}_{4} \mathrm{VO}_{3}$ (514 nm excitation).

there are still many unanswered questions, this literature attempts to address how the vanadate coordination, surface coverage, and speciation relate to such redox reactions. Vanadia catalysts are most frequently employed for reactions such as the oxidative dehydrogenation of light alkanes to alkenes or the oxidation of alcohols to aldehydes, however, they also are employed as catalysts in the reduction of various $\mathrm{NO}_{\mathrm{x}}$ compounds. ${ }^{28,36}$ It is generally believed that the catalyzed oxidation processes involve the oxidation of the desired hydrocarbon accompanied by the reduction of $\mathrm{O}_{2}$ via an exchange of oxygen atoms within the vanadate species during which catalytic process the vanadium cycles from $\mathrm{a}+5$ to $\mathrm{a}+4$ and back to $a+5$ oxidation state. ${ }^{28}$ Bell and co-workers noted that oxidative catalysis of hydrocarbons proceeds at somewhat higher rates when alumina supported vanadates are polymerized versus supported monovanadates species. ${ }^{28}$ Of special consideration for vanadates on aluminum alloys are the findings of Owen and Kung. ${ }^{30,31}$ These researchers studied the catalytic selectivity of orthovanadates of various metal cations such as $\mathrm{Mg}, \mathrm{Zn}, \mathrm{Cr}, \mathrm{Ni}, \mathrm{Cu}$, and $\mathrm{Fe}$. Notably, they were able to collect reproducible data on selective catalysis on the orthovanadates of all the cations except copper. While attempting to measure catalytic behavior on $\mathrm{Cu}_{3}\left(\mathrm{VO}_{4}\right)_{2}$, "it was found that this catalyst underwent relatively rapid deactivation." Furthermore,

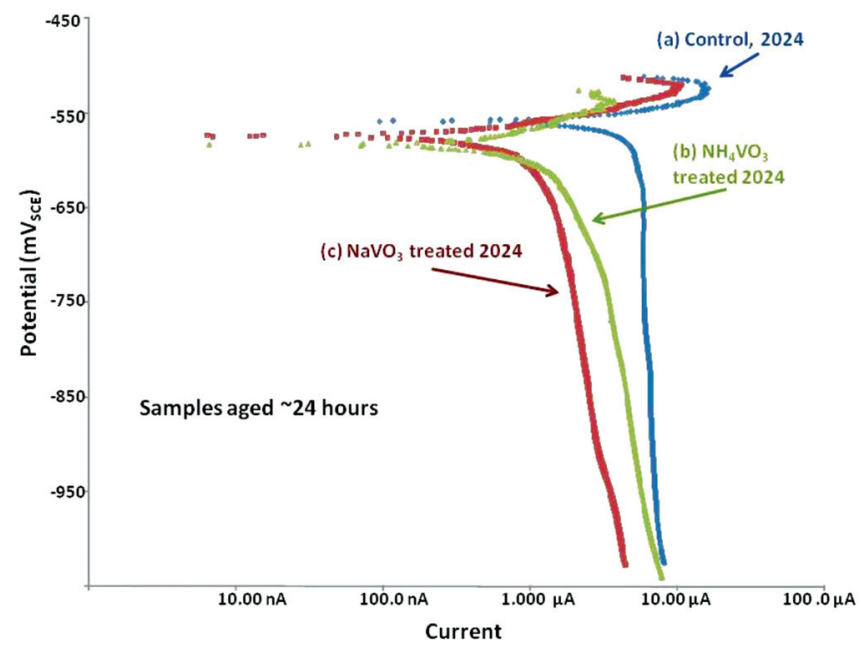

Figure 6. (Color online) Potentiodynamic scans performed in $0.1 \mathrm{M} \mathrm{NaCl}$ of: (a) untreated 2024, (b) 2024 pre treated with $\mathrm{NH}_{4} \mathrm{VO}_{3}$, (c) 2024 pre treated with $\mathrm{NaVO}_{3}$.

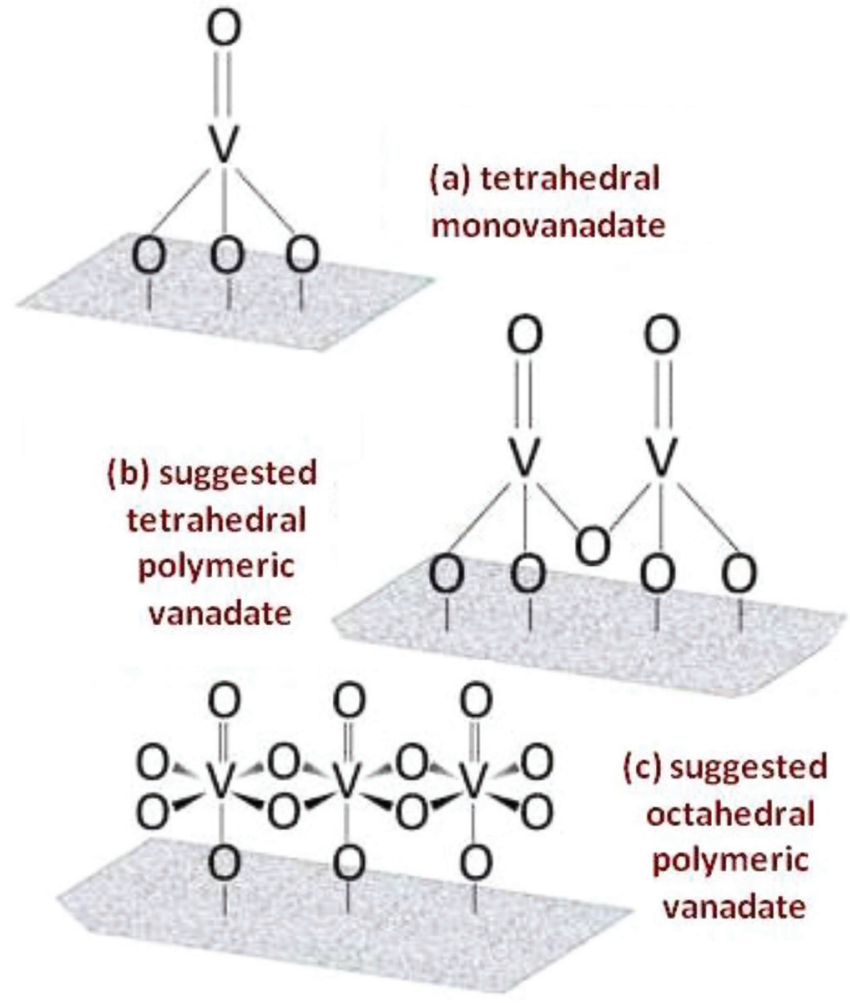

Figure 7. (Color online) Suggested vanadate surface species. (a) monovanadates, (b) tetrahedral polyvanadate (c) octahedral polyvanadate.

unlike the other orthovanadate compounds "the deactivated [copper orthovanadate] catalyst could not be regenerated by treatment with $\mathrm{O}_{2} .{ }^{, 30}$ These findings suggest a difference in the manner in which redox reactions might occur on vanadate-treated copper-rich particles versus similarly treated matrix areas of 2024 . The above spectroscopic results also indicate a difference in the manner in which vanadates interact with copper-rich particles versus the matrix of 2024. Several key findings related to these differences are noted below.

The reference spectra for various vanadate species (Fig. 1) notably all display a strong, sharp band between 940 and $1000 \mathrm{~cm}^{-1}$. This band is attributed to the terminal $\mathrm{V}=\mathrm{O}$ stretch in tetrahedrally coordinated vanadate species. ${ }^{41}$ Specifically, the $\mathrm{V}=\mathrm{O}$ stretch for $\mathrm{V}_{2} \mathrm{O}_{5}, \mathrm{~V}_{2} \mathrm{O}_{4}$, and $\mathrm{VO}_{2}$, the most stable neutral vanadate species, appears strongly and distinctly at $993-994 \mathrm{~cm}^{-1}$. A similar $\mathrm{V}=\mathrm{O}$ stretch for octahedrally coordinated amorphous polyvanadate species is expected to display in the range between $890-950 \mathrm{~cm}^{-1}$. 36 The strong, sharp terminal $\mathrm{V}=\mathrm{O}$ stretch in $\mathrm{Cu}_{3}\left(\mathrm{VO}_{4}\right)_{2}$ appears at $850-867 \mathrm{~cm}^{-1} \cdot 30,34$ Of particular importance to this work, Wachs et al.. attribute a broad band from $750-1000 \mathrm{~cm}^{-1}$ to V-O-V stretches in two-dimensional distorted polyvanadates. ${ }^{28,35,42}$ As noted above, a similar band appears on copper-rich intermetallic particles treated with basic solutions of $\mathrm{NaVO}_{3}$ (containing tetrahedrally coordinated vanadates) but is absent from copper-rich intermetallic particles treated with acidic solutions of $\mathrm{NH}_{4} \mathrm{VO}_{3}$ (containing octahedrally coordinated vanadates). ${ }^{1,5}$

Previous studies on vanadate-treated alumina employed for catalytic processes have placed an emphasis on the difference between monovanadates surface species and polyvanadate species, such as those shown in Fig. 7. ${ }^{29,35,42-45}$ In the case of the polymeric vandate species for these catalytic surfaces, it was found that the degree of polymerization increased as the loading of vanadate on alumina increased, and, therefore, an extension of the polymerization of the representative species shown in Figs. $7 \mathrm{~b}$ and $7 \mathrm{c}$ can be assumed. ${ }^{43}$ Additionally, previous investigations indicate that the coordination 
of polymerized vanadates on alumina supports evolves from tetrahedral coordination at low coverage to octahedral coordination at higher coverage. ${ }^{29,44,45}$ As discussed in more detail below, although extensive Raman analysis of these surfaces has been undertaken over a period of well over a decade, conclusive speciation and bonding parameters remain elusive. ${ }^{25,27-36}$ It has been concluded, however, that the terminal $\mathrm{V}=\mathrm{O}$ bond in monovanadates species results in a sharp band in the range of $1020-1050 \mathrm{~cm}^{-1} \cdot 29,35,42$ Furthermore, as also discussed below, a broad and between 750 and $1000 \mathrm{~cm}^{-1}$ is attributed to the $\mathrm{V}-\mathrm{O}-\mathrm{V}$ stretch in two-dimensional distorted polyvanadates. $29,35,42,44,45$

The Raman data presented in Fig. 2 indicate the expected presence of $\mathrm{Cu}_{2} \mathrm{O}\left(525 / 613 \mathrm{~cm}^{-1}\right.$ bands) on the control area of the rod and only very weak scattering from those bands on the reduced area $\left(\mathrm{Cu}^{0}\right)$ of the rod. It should be noted that the holding potential of $-600 \mathrm{mV}$ was chosen to ensure the reduction of the copper surface, but of equal importance is that this potential is also similar to the expected OCP of 2024 and the copper-rich intermetallic particles in 2024 in a dilute $\mathrm{NaCl}$ solution. ${ }^{46}$ Additionally, the reduced area on the rod shows only very weak scattering in the range from 700-900 $\mathrm{cm}^{-1}$, the expected range for scattering from vanadate species. Conversely, the $\mathrm{Cu}_{2} \mathrm{O}$ area of the rod exposed to vanadate displays a strong band attributable to vanadate surface species. Although the exact nature of the species cannot be deduced from this data, two conclusions can be drawn: (1) the strong, broad peak between 650 and $1000 \mathrm{~cm}^{-1}$ with a maximum at $763 \mathrm{~cm}^{-1}$ strongly suggests the presence of polymerized vanadate and (2) based on Kung's work, above, the strong shoulder at $\sim 840 \mathrm{~cm}^{-1}$ supports the possible presence of a tetrahedrally coordinated copper vanadate species similar to $\mathrm{Cu}_{3}\left(\mathrm{VO}_{4}\right)_{2}$. Although the data clearly support the presence of vanadate species on the treated $\mathrm{Cu}_{2} \mathrm{O}$ surface, they neither preclude nor confirm the presence of both polymerized and tetrahedrally coordinated monovanadates. The extreme weakness of the band in the range for vanadate species noted on the reduced area of the rod combined with the weak scattering from $\mathrm{Cu}_{2} \mathrm{O}$ on the reduced area imply the inability of vanadate species to form on or adsorb to a reduced $\left(\mathrm{Cu}^{0}\right)$ copper surface. Assuming a likely $\mathrm{Cu}-\mathrm{O}-\mathrm{V}$ surface bond (though not necessarily covalent), this, in turn, suggests that oxygen from $\mathrm{Cu}_{2} \mathrm{O}$ plays an important role in surface bonding or adsorption.

The control spectra of the matrix and a copper-rich particle on 2024 provide two distinctive and useful markers. The Raman microprobe's 50X objective samples an approximately 3-6 $\mu \mathrm{m}$ diameter area. Additionally, the microprobe provides for visual inspection of an approximately $100 \times 150 \mu \mathrm{m}$ area. Therefore, spectra can be distinctly identified as originating from either the matrix or an intermetallic particle (Fig. 8). The composition of an intermetallic particle, however, cannot be ascertained via visual inspection. As noted above, copper-rich particles were therefore identified by the presence of the distinctive $525 / 613 \mathrm{~cm}^{-1}$ bands, clearly present in the spectrum of an untreated copper-rich intermetallic particle in Fig. 3. Furthermore, spectra of the matrix were additionally validated via the presence of a sharp peak at $588 \mathrm{~cm}^{-1}$ attributable to aluminum oxide (Fig. 3).

The sharp, but weak peak at $1036 \mathrm{~cm}^{-1}$ in spectra of 2024 matrix treated with $\mathrm{NaVO}_{3}$ (Fig. 4) indicates the presence of monovanadates species. Wachs et al. and Bell et al. reported that the sharp, terminal $\mathrm{V}=\mathrm{O}$ stretch arising from monovanadates species supported on alumina ranges from $\sim 1024 \mathrm{~cm}^{-1}$ for low coverage of isolated monovanadates to $\sim 1032 \mathrm{~cm}^{-1}$ with increasing surface density of monovanadates. ${ }^{28,35,42}$ Additionally, the absence or weakness of any broad band scattering (above that of the background scattering noted in the control spectrum) between 750 and $1000 \mathrm{~cm}^{-1}$ originating from treated matrix suggests limited or no formation of polyvanadate species on the matrix area. Finally, although the small, sharp peak appearing at $815 \mathrm{~cm}^{-1}$ is presumably due to a terminal $\mathrm{V}=\mathrm{O}$ stretch, the specific vanadate species of its origin is unknown.

In contrast, the strong, broad scattering between $700-980 \mathrm{~cm}^{-1}$ observed in spectra of copper-rich particles treated with $\mathrm{NaVO}_{3}$

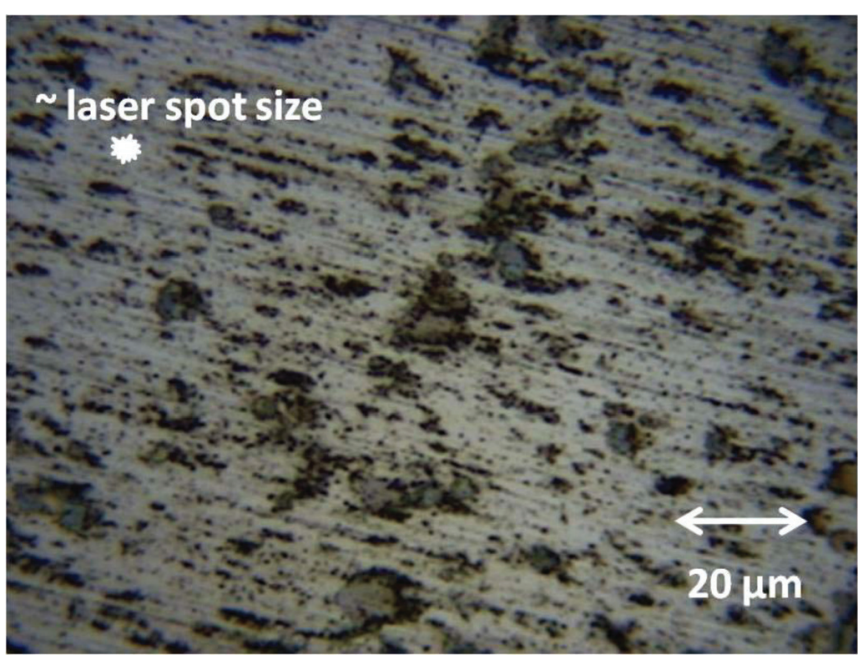

Figure 8. (Color online) Raman microprobe image of 2024.

confirms the presence of polyvanadates on the copper-rich particles (Fig. 4). Notably absent from the spectra of these treated particles is the presence of any band between 1000 and $1050 \mathrm{~cm}^{-1}$, suggesting the absence of any monovanadates species on these particles, as had been observed on the treated matrix. In keeping with the above noted references, ${ }^{29,44,45}$ it should be noted that the polyvanadates observed on the copper-rich intermetallic particles presumably contain octahedral centers under conditions of high coverage and tetrahedral centers under conditions of low coverage. The monovanadates observed on the matrix contain tetrahedral centers. This does not contradict the work of Frankel et al. or Buchheit et al. (mentioned above and discussed in more detail below) indicating corrosion inhibition arising from treatment with aqueous tetrahedral vanadate species. ${ }^{1-7}$ In fact, evidence of polyvanadates was absent on copper-rich intermetallic particles treated with the acidic (octahedrally coordinated) $\mathrm{NH}_{4} \mathrm{VO}_{3}$ solution. This suggests that the basic, tetrahedrally coordinated $\mathrm{NaVO}_{3}$ solution was necessary to form octahedrally (and tetrahedrally) coordinated polyvanadates on the intermetallic particles. If, indeed, tetrahedrally coordinated vanadates in treatment solution are key to corrosion inhibition, the basic local environment at copper-rich intermetallic particles arising from the ORR would work in favor of maintaining reservoirs of

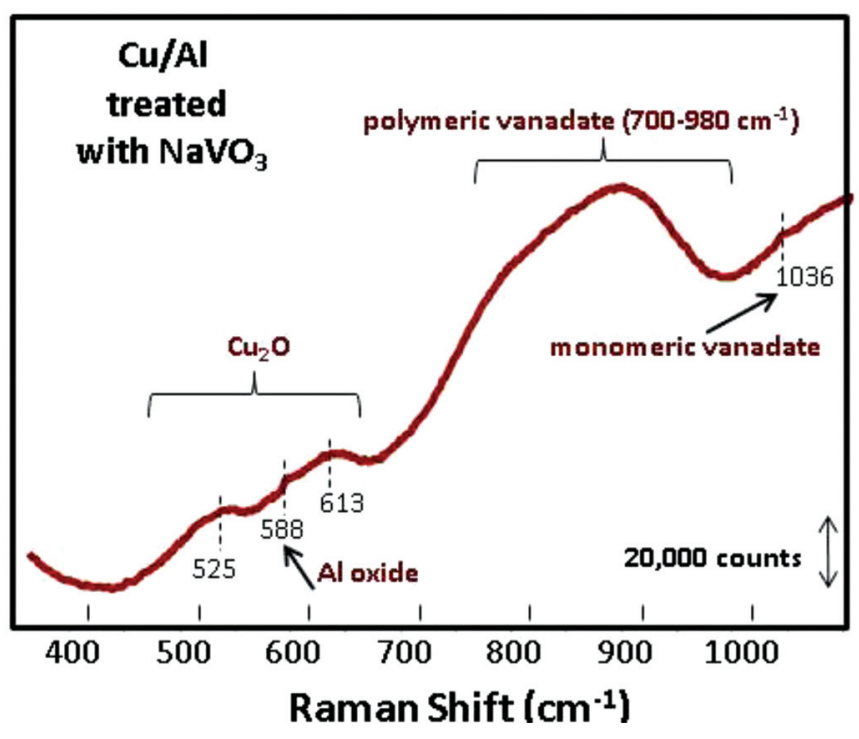

Figure 9. (Color online) Raman spectrum of area on 2024 containing both aluminum oxide and $\mathrm{Cu}_{2} \mathrm{O}$ and treated with $\mathrm{NaVO}_{3}(514 \mathrm{~nm}$ excitation). 
tetrahedrally coordinated vanadates or converting reservoirs of octahedrally coordinated vanadates to tetrahedral coordination.

Of note and related to the difference between treated matrix versus copper-rich particles is a spectrum of a treated copper-rich particle displaying the $\mathrm{Cu}_{2} \mathrm{O}$ bands at $525 / 613 \mathrm{~cm}^{-1}$ and also displaying the distinctive $588 \mathrm{~cm}^{-1}$ peak arising from aluminum oxide (Fig. 9). The presence of both the $525 / 613 \mathrm{~cm}^{-1}$ bands and the $588 \mathrm{~cm}^{-1}$ peak suggests either a copper-rich particle with some aluminum oxide covering or the possibility that the microprobe was collecting scattering from both a copper-rich particle and some adjacent matrix area. Regardless of the origin of the "mixed" scattering, the spectrum arising from this "mixed" treated area displayed both the strong, broad band between $700-980 \mathrm{~cm}^{-1}$ and the distinctive sharp peak at $1036 \mathrm{~cm}^{-1}$, indicating the presence of both polyvanadate and monovanadates species in agreement with a combination of the individual findings for each type area.

Neither the spectra of matrix treated with $\mathrm{NaVO}_{3}$ nor those of copper-rich particles treated with $\mathrm{NaVO}_{3}$ display any of the exceptionally strong, sharp bands at $943 \mathrm{~cm}^{-1}$ or $993-994 \mathrm{~cm}^{-1}$ present in the reference vanadate species, inferring that solid vanadate residue is not present on the samples. Although the spectra of both areas contain some broad scattering from approximately $700-950 \mathrm{~cm}^{-1}$, the strong cross-section of the reference species would be expected to easily result in sharp peaks extending above either the matrix background or the scattering arising from polyvanadate species on copper-rich particles if a solid vanadate residue species were present.

Previous corrosion inhibition studies involving vanadates have primarily involved the use of $\mathrm{NaVO}_{3}$ as a starting material, however, $\mathrm{NH}_{4} \mathrm{VO}_{3}$ is often the vanadate salt of choice for studies of alumina-supported vanadia as a catalyst. ${ }^{29,32}$ For the present work, 2024 samples were treated with an $\mathrm{NH}_{4} \mathrm{VO}_{3}$ /oxalic acid solution in a manner similar to that used for catalysis experiments. As noted below, the resulting samples displayed modest inhibition similar to samples treated with $\mathrm{NaVO}_{3}$ during cathodic polarization of unaged samples, however, spectra of samples treated with $\mathrm{NH}_{4} \mathrm{VO}_{3}$ were somewhat different than those treated with $\mathrm{NaVO}_{3}$. In particular, as shown in Fig. 5, spectra of the matrix of 2024 treated with $\mathrm{NH}_{4} \mathrm{VO}_{3} /$ oxalic acid were very similar to that of the matrix treated with $\mathrm{NaVO}_{3}$ (Fig. 4) with a somewhat stronger rise in the scattering between $750-980 \mathrm{~cm}^{-1}$, implying the presence of some polyvanadate species on the matrix. Spectra of copper-rich particles treated with $\mathrm{NH}_{4} \mathrm{VO}_{3}$ /oxalic acid, however, were quite different. Specifically, these spectra displayed virtually no scattering in the 750-980 $\mathrm{cm}^{-1}$ range, suggesting the absence of polyvanadate species on the particles.

It is possible that the differences observed in the results of the treatment with the two different salts arise from the difference in cation, particularly the reactivity of $\mathrm{NH}_{4}^{+}$versus that of $\mathrm{Na}^{+}$. More likely is that the differences arise from the difference in $p \mathrm{H}$ of the two solutions and the effects this difference could have on vanadate solution species and the metal surface during the treatment process. As noted above, Frankel et al. and Buchheit et al. found that the tetrahedrally coordinated forms of vanadate found in basic solutions act as corrosion inhibitors on aluminum alloys while the octahedrally coordinated forms of vanadate found in acidic solutions do not act as significant corrosion inhibitors. ${ }^{1-7}$ The slightly basic $p \mathrm{H}$ ( $~ 8)$ of the $\mathrm{NaVO}_{3} / \mathrm{NaCl}$ solution used to treat the 2024 samples that formed polyvanadates on copper-rich particles would have predominantly contained the favored tetrahedrally coordinated vanadate species while the acidic $p \mathrm{H}(\sim 3)$ of the $\mathrm{NH}_{4} \mathrm{VO}_{3}$ /oxalic acid solution that did not appear to form polyvanadates on copper-rich particles would have predominantly contained non-corrosion inhibiting octahedrally coordinated vanadate species. ${ }^{1,5}$

Previous work by Ralston et al. showed inhibition of cathodic current of over an order of magnitude on 2024 samples subjected to cathodic polarization scans from -500 to $-1700 \mathrm{mV}_{\mathrm{SCE}}$ in $0.05 \mathrm{M}$ $\mathrm{NaCl}$ solutions containing a low concentration $(0.003 \mathrm{M})$ of $\mathrm{NaVO}_{3}$ versus samples polarized in $0.05 \mathrm{NaCl}^{1}$ In the present work, ca- thodic polarization scans performed on 2024 samples pre-treated with either $\mathrm{NaVO}_{3} / \mathrm{NaCl}$ or $\mathrm{NH}_{4} \mathrm{VO}_{3} /$ oxalic acid, rinsed, aged, and scanned in $0.1 \mathrm{M} \mathrm{NaCl}$, displayed modest cathodic inhibition when samples were aged $\sim 24 \mathrm{~h}$ after rinsing under ambient conditions (Fig. 6). Upon aging for $\sim 96 \mathrm{~h}$, however, neither of the treatments displayed cathodic inhibition. Raman spectral analysis (not shown) of 2024 copper-rich intermetallic particles treated as noted immediately above with $\mathrm{NaVO}_{3}$ and aged for 96-144 h are virtually identical to those shown in Fig. 4b, with the exception that the band between 700 and $980 \mathrm{~cm}^{-1}$ is present, but greatly diminished. All spectra in Figs. 3, 4, 5, and 9 were acquired within $24 \mathrm{~h}$ of treatment. These results suggest the possibility of some type of breakdown in the vanadate surface coverage with time when the surface is exposed to ambient conditions. Both the electrochemical and spectroscopic data, therefore, suggest that for surface vanadates to provide successful corrosion inhibition, a treatment that prevents deterioration of the vanadate film could be of importance.

\section{Conclusions}

1. Vanadate species are significantly more likely to form on a $\mathrm{Cu}_{2} \mathrm{O}$ surface than on a reduced copper $\left(\mathrm{Cu}^{0}\right)$ surface when such surfaces are treated with an aqueous $\mathrm{NaVO}_{3}$ solution under potentiostatic control at a potential similar to that of 2024 copper-rich intermetallic particles in dilute $\mathrm{NaCl}$ solution, implying an important role for oxygen contained in $\mathrm{Cu}_{2} \mathrm{O}$ in the formation of vanadate species on copper-rich intermetallic particles. Additionally, the vanadate species that form on a $\mathrm{Cu}_{2} \mathrm{O}$ surface under these conditions are most likely polymerized, although the presence of monovanadate species on the $\mathrm{Cu}_{2} \mathrm{O}$ surface or in combination with the vanadate polymer cannot be excluded.

2. Upon treatment of 2024 with aqueous $\mathrm{NaVO}_{3} / \mathrm{NaCl}$ solution under OCP conditions, a polymerized vanadate species forms on copper-rich intermetallic particles. The formation of monovanadate species on such particles under these conditions is not supported by this work.

3. Upon treatment of 2024 with aqueous $\mathrm{NaVO}_{3} / \mathrm{NaCl}$ solution under OCP conditions, high coverage of monovanadate species form on the aluminum oxide matrix accompanied by little or no formation of polymerized vanadate species.

4. The formation of polymerized vanadate species on copperrich intermetallic particles supports the previously reported cathodic inhibition mechanism. ${ }^{1-5,7}$

5. Upon treatment of 2024 with aqueous $\mathrm{NH}_{4} \mathrm{VO}_{3}$ /oxalic acid solution under OCP conditions, high coverage of monovanadate species form on the aluminum oxide matrix accompanied by little or no formation of polymerized vanadate species.

6. The presence of polymerized vanadate species on copper-rich intermetallic particles treated with aqueous $\mathrm{NaVO}_{3} / \mathrm{NaCl}$ solution versus the lack of evidence for similar species on particles treated with aqueous $\mathrm{NH}_{4} \mathrm{VO}_{3}$ /oxalic acid solution supports the importance of a tetrahedrally coordinated vanadate species in solution during the treatment process.

7. 2024 samples pre-treated with either an aqueous $\mathrm{NaVO}_{3} / \mathrm{NaCl}$ solution or an aqueous $\mathrm{NH}_{4} \mathrm{VO}_{3}$ /oxalic acid solution display modest cathodic inhibition soon after treatment, but inhibition degrades with time.

\section{Acknowledgments}

The authors thank Dr. Kevin Ralston for valuable consultations and comments regarding this work. This Project is sponsored by SERDP under contract no. WH912HQ-08-C-0011. Purchase of the Raman microprobe was supported by the National Science Foundation under grant no. 0639163.

The Ohio State University assisted in meeting the publication costs of this article. 


\section{References}

1. K. D. Ralston, S. Chrisanti, T. L. Young, and R. G. Buchheit, J. Electrochem. Soc., 155, C350 (2008)

2. K. D. Ralston, T. L. Young, and R. G. Buchheit, J. Electrochem. Soc., 156, C135 (2009).

3. M. Iannuzzi and G. S. Frankel, Corros. Sci., 49, 2371 (2007).

4. M. Iannuzzi, T. Young, and G. S. Frankel, J. Electrochem. Soc., 153, B533 (2006).

5. M. Iannuzzi and G. S. Frankel, ECS Trans., 3 (31), 127 (2007).

6. M. Iannuzzi and G. S. Frankel, Corrosion (Houston), 63, 672 (2007).

7. M. Iannuzzi, J. Kovac, and G. S. Frankel, Electrochim. Acta, 52, 4032 (2007).

8. S. Surnev, M. G. Ramsey, and F. P. Netzer, Prog. Surf. Sci., 73, 117 (2003).

9. H. Guan and R. G. Buchheit, Corrosion (Houston), 60, 284 (2004).

10. S. P.V. Mahajanam and R. G. Buchheit, Corrosion (Houston), 64, 230 (2008)

11. T. H. Muster, A. E. Hughes, and G. E. Thompson, in Corrosion Research Trends, I. S. Wang, Editor, p. 35, Nova Science Publishers, Inc., Hauppauge, NY (2007).

12. I. J. Polmear, Light Alloys Metallurgy of the Light Metals, Arnold, London (1995).

13. N. Birbilis and R. G. Buchheit, J. Electrochem. Soc., 152, B140 (2005).

14. T. J. R. Leclere, A. J. Davenport, and R. C. Newman, Corrosion (Houston), 63, 338 (2007)

15. T. J. R. Leclere and R. C. Newman, J. Electrochem. Soc., 149, B52 (2002)

16. M. A. Alodan and W. H. Smyrl, J. Electrochem. Soc., 145, 1571 (1998).

17. R. G. Buchheit, R. P. Grant, P. F. Hlava, B. McKenzie, and G. L. Zender, J. Electrochem. Soc., 144, 2621 (1997).

18. G. S. Chen, M. Gao, and R. P. Wei, Corrosion, 52, 8 (1996)

19. N. Dimitrov, J. A. Mann, M. Vukmirovic, and K. Sieradzki, J. Electrochem. Soc., 14, $3283(2000)$.

20. M. Gao, C. R. Feng, and R. P. Wei, Metall. Mater. Trans. A, 29A, 1145 (1998).

21. G. O. Ilevbare and J. R. Scully, J. Electrochem. Soc., 148, B196 (2001).

22. M. Vukmirovic, N. Dimitrov, and K. Sieradzki, J. Electrochem. Soc., 149, B428 (2002).

23. W. J. Clark and R. L. McCreery, J. Electrochem. Soc., 149, B379 (2002).

24. B. L. Hurley and R. L. McCreery, J. Electrochem. Soc., 150, B367 (2003).
25. L. E. Briand, J.-M. Jehng, L. Cornaglia, A. M. Hirt, and I. E. Wachs, Catal. Today, 78, 257 (2003).

26. M.-J. Cheng, K. Chenoweth, J. Oxgaard, A. Van Duin, and W. A. Goddard III, J. Phys. Chem. C, 111, 5115 (2007).

27. A. Khodakov, B. Olthof, A. T. Bell, and E. Iglesia, J. Catal., 181, 205 (1999).

28. B. Kilos, A. T. Bell, and E. Iglesia, J. Phys. Chem. C, 113, 2830 (2009).

29. B. Olthof, A. Khodakov, A. T. Bell, and E. Iglesia, J. Phys. Chem. B, 104, 1516 (2000).

30. O. S. Owen and H. H. Kung, J. Mol. Catal., 79, 265 (1993).

31. O. S. Owen, M. C. Kung, and H. H. Kung, Catal. Lett., 12, 45 (1992).

32. S. T. Oyama, G. T. Went, K. B. Lewis, A. T. Bell, and G. A. Somorjai, J. Phys. Chem., 93, 6786 (1989).

33. F. Roozeboom, M. C. Mittelmeijer-Hazeleger, J. A. Moulijn, J. Medema, V. H. J. De Beer, and P. J. Gellings, J. Phys. Chem., 84, 2783 (1980).

34. K. Routray, L. E. Briand, and I. E. Wachs, J. Catal., 256, 145 (2008).

35. I. E. Wachs, Catal. Today, 27, 437 (1996).

36. G. T. Went, S. T. Oyama, and A. T. Bell, J. Phys. Chem., 94, 4240 (1990).

37. A. Kudelski, M. Janik-Czachor, J. Bukowska, M. Dolata, and A. Szummer, J. Mol. Struct., 482-483, 245 (1999).

38. B. L. Hurley, Ph.D. Thesis, The Ohio State University (2004).

39. H. Y. H. Chan, C. G. Takoudis, and M. J. Weaver, J. Phys. Chem. B, 103, 357 (1999).

40. F. Texier, L. Servant, J. L. Bruneel, and F. Argoul, J. Electroanal. Chem., 446, 189 (1998).

41. F. D. Hardcastle and I. E. Wachs, J. Phys. Chem., 95, 5031 (1991).

42. M. A. Vuurman and I. E. Wachs, J. Phys. Chem., 96, 5008 (1992).

43. L. J. Burcham, G. Deo, X. Goa, and I. E. Wachs, Top. Catal., 11/12, 85 (2000).

44. H. Eckert and I. E. Wachs, J. Phys. Chem., 93, 6796 (1989).

45. L. R. Le Coustumer, B. Taouk, M. Le Meur, E. Payen, M. Guelton, and J. Grimblot, J. Phys. Chem., 92, 1230 (1988)

46. R. G. Buchheit, J. Electrochem. Soc., 142, 3994 (1995).

47. S. P. Best, R. S. Armstrong, and J. K. Beattie, Inorg. Chem., 19, 1958 (1980). 